\title{
Contrasting Assessed and Perceived Risk: A Case Study of Two Rapidly Increasing Cancers in Taiwan
}

\author{
Chi Pang Wen ${ }^{* 1,2}$, Yi Chen Yang ${ }^{2}$, Min Kuang Tsai ${ }^{2}$ and Yen Chen Chang ${ }^{2}$ \\ ${ }^{1}$ China Medical University Hospital, Taichung, Taiwan \\ ${ }^{2}$ Institute of Population Health Sciences, Division of Health Policy, National Health Research Institutes, Zhunan, \\ Taiwan
}

\begin{abstract}
There are unfortunate cases in public health where a scientifically determined assessment of risk presented to the public is neglected in favor of pre-conceived notions of risk. In clinical settings, risk perception is important but often ignored by practitioners. The consequences of this are varied and could be devastating. Most clinicians are not trained in communicating clinical risks, and patients may be forced to make decisions based on the risk they perceive rather than the actual risk. A rational decision would require full information expressed in terms of absolute risk as well as relative risk. As new media becomes more pervasive, the gap between assessed and perceived risk widens and society is paying a price for this phenomenon not being addressed.

Two types of cancers are used to illustrate this point. Both have been increasing rapidly in the last 20 years in Taiwan for reasons related to risk perception. Risks from these two cancers were misread by the public, resulting in thousands of unnecessary deaths. Due to public misperceptions, the actual risk was mistakenly minimized in one instance, and unknowingly enhanced in another.

Chewers of betel quid (BQ) belittle the risk of oral cancer, perceiving it is a known, future, familiar but controllable risk. Unfortunately, thousands die each year from BQ chewing because millions continue to chew. On the other hand, the fear of prostate cancer has led to screening tests that may cause physical and psychological harm. With the availability of PSA tests to detect prostate cancer, increasing numbers of elderly men pursue biopsy and treatment. Even though the actual risk from prostate cancer is small, the demand for zero risk has compelled worried patients to endure the agony of intervention and to suffer serious side effects because the treatment intended to reduce risk may instead increase morbidity and mortality. The fact that there may be substantial harm, with uncertain health benefits, from unnecessary treatment has been publicized, but clinicians have ignored fully communicating pros and cons of treatment to patients.

Mainstream risk assessment, mostly for regulatory purposes, has focused on toxic substances often involving small risks at current occupational and environmental exposure levels. Most of these assessments address risk at a magnitude between one per thousand and one per million. Risks in clinical settings are often several orders of magnitude higher, such as the risk for smokers who have a one in three lifetime risk of dying from smok-ingrelated diseases. The irony is that the general public is far more concerned with risk from toxic substances than lifestyle or clinical risks. This discrepancy is a major health threat and should alarm risk assessors who are pursuing technological excellence on a continuing basis but neglecting risk communication. Effective risk communication in clinical settings should be a required discipline for clinicians. This training should address the gap between perceived risk, commonly dominated by pre-conceived notions, and actual risk, derived from evidence-based data.
\end{abstract}

Keywords: Risk assessment, risk perception, oral cancer, prostate cancer, betel quid, PSA screen test, Taiwan.

\section{INTRODUCTION}

Risk assessments, more often than not, are conducted in the absence of sufficient human data. Most regulations are based on the assessment of human risk through extrapolation of animal studies. Because human environmental and occupational exposure to toxic substances is frequently at a very low concentration, the level of risk assessed in the regulatory realm has been in the order of one death in a million to one death in a thousand. This one in a million risk

*Address correspondence to this author at the Institute of Population Health Sciences, Division of Health Policy Research and Development, National Health Research Institutes, 35 Keyan Rd., Zhunan, Taiwan; Tel: 886-37246-166, Ext. 36318; E-mail: cwengood@nhri.org.tw level is usually dwarfed by risks that may be related to behavioral or genetic factors (e.g. driving, smoking, physical activity or inactivity, obesity, cancer, hypertension, diabetes), which are in the order of one death in a hundred to one death in ten. When we communicate an environmental risk level assessed at one per million, it is important to remind our audience of the fact that we may be facing a daily risk of one per hundred from our lifestyle. Quite often, one is pre-occupied or distracted by whether risk greater than one per million is acceptable or not. While this risk is real and often very serious, it usually is not described by its magnitude relative to other known risks. Regulatory risk assessment requirements exist, e.g., on workers' exposure in the workplace, and yet, no policy exists requiring someone to interpret these risks in plain language to the public. 
Epidemiology, the science behind assessment of real life risks, uses morbidity or mortality data extensively by taking past human experience into account in order to project future risk. In this paper, we use two "real life" examples to illustrate how risks were assessed using epidemiological data. The lesson learned is that we should not be ending an assessment with publication, but more importantly, looking into how it was perceived and how it can be communicated more effectively to both policy makers and the public at large. The challenge is to see how the assessed risk can be employed to change the perceived risks. Lessons and implications learned here should be shared with other risk assessors so that real life complexities can be better understood. The number of deaths from two types of cancer (Fig. 1) have been rapidly increasing in Taiwan in the last 20 years: oral cancer and prostate cancer [1]. The number of oral cancer deaths (in males) increased 6-fold, from 349 in m1986 to 2,079 in 2008, and age-adjusted mortality rate increased 3-fold. The number of prostate cancer deaths increased 7-fold, from131 in 1986 to 980 in 2008, and ageadjusted mortality rate increased 3 -fold (Table 1) [2]. Of relevance to this observation is the fact that incidence rates for both types of cancers increase faster than mortality rates. The incidence rate of oral cancer increased nearly 5 -fold while the death rate increased 3 -fold. The incidence rate for prostate cancer increased 4-fold, while the death rate increased only 3-fold (Fig. 1).

Based on epidemiological data, oral cancer is more serious than prostate cancer for two reasons: first, the ageadjusted rate of oral cancer deaths was more than twice that from prostate cancer (Fig. 1), and second, the median age of deaths from oral cancer, 54, was 25 years younger than that from prostate cancer, 80 (Table 1) [2]. While death at a younger age may have more societal impact, behavior in Taiwan suggests that the public perceived oral cancer risk as more acceptable than prostate cancer risk. As will be demonstrated in this paper, the public viewed risk of prostate cancer death as unacceptable, demanding zero risk.

Out of fear of the unknown risk of prostate cancer, male adults, young and old, request PSA screening tests. Upon
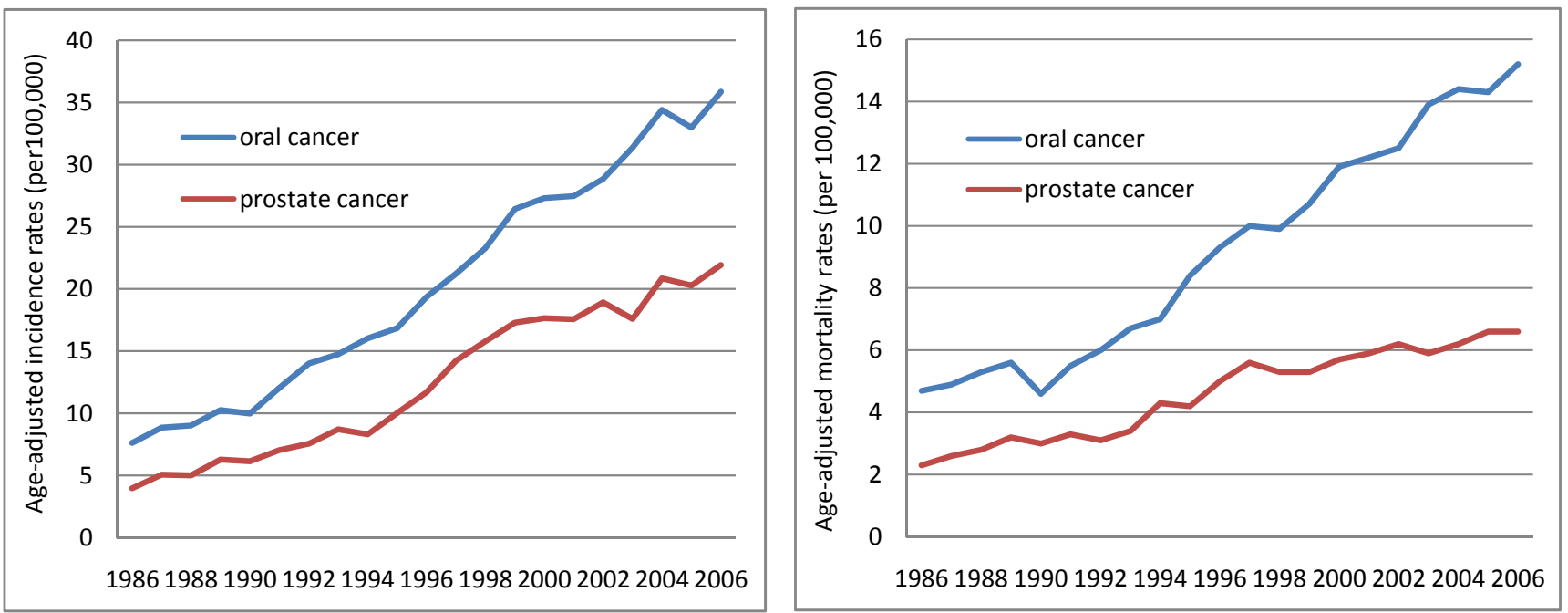

Fig. (1). Increasing trend of incidence rates and mortality rates of oral cancer and prostate cancer in Taiwan during 1986-2006, using the WHO 2000 population as standard. testing, they only learn of their PSA value, an unfamiliar number to most individuals. Invariably, the PSA test gets interpreted by someone who claims to be an authorityon its implications and makes a determination as to whether one should have a biopsy procedure for confirming the presence of prostate cancer. Once prostate cancer is found from the biopsy, most proceed to request and pursue the elimination of the cancer, without realizing that such a process involves substantial risks. Side effects can include increasedmorbidity, e.g., incontinence and impotence, and death. In summary, PSA screening can identify elevated PSA, which could lead to a positive biopsy, resulting in increased prostate cancer incidence. A postivie biopsy would force one into surgical cancer treatment, possibly resulting in increased morbidity and excess mortality. All of this occurs because of the perceived risk of prostate cancer and the commitment to eliminate that "socially unacceptable" risk. In contrast, chewers and smokers often picked up their habits in their late teens to early 20s and became addicted at young ages [3]. They continued to chew and smoke, day in and day out, year after year, with no fear of immediate cancer risk. They view the behavior as controllable and the health risk "socially acceptable." Similar to the publicized lung cancer risk from smoking, the role of chewing in causing oral cancer has been communicated to most chewers. Being somewhat familiar with oral cancer, chewers believe they have the risk under their control, as long as they have no health problems. The 10 to 20 year latency for oral cancer is another factor which causes them to perceive risk as minimal. Risk assessments, mostly based on life-time risk, do not take event time into consideration. Immediate risk is perceived as much more serious than a future one. Epidemiological data show that after years of BQ chewing and smoking, the behavior leads to a large increase in cancer and non-cancer health effects attributable to these two risk factors, including oral cancer and esophageal cancer [4-7].

Why did such a paradoxical discrepancy between real and perceived risk develop? While public health workers watched in despair the increasing cancer mortality resulting from misperception of risk, chewing has caused 20,000 all cause deaths a year in Taiwan [8]. For prostate cancer, it 

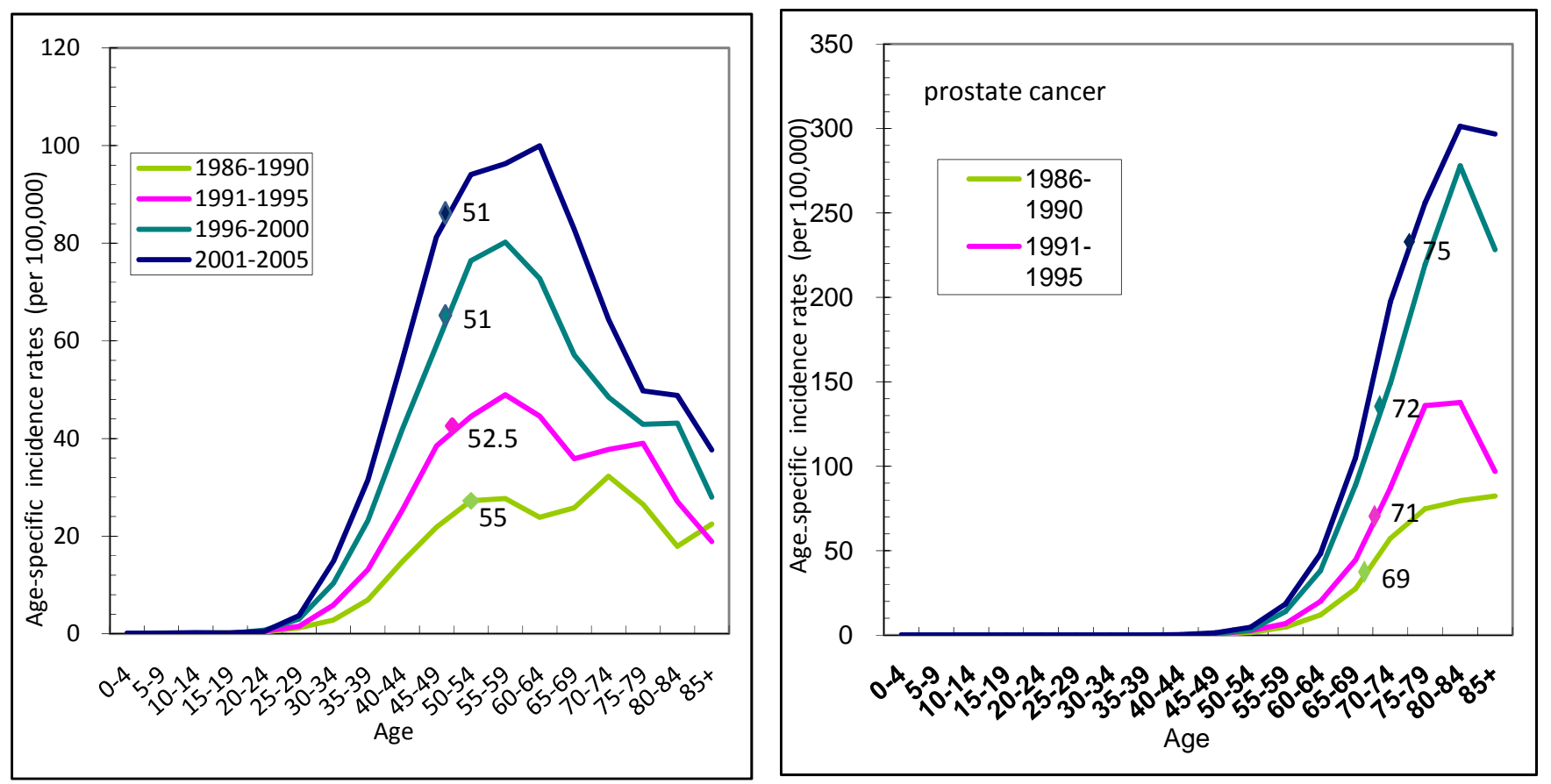

Fig. (2). Incidence rate for oral cancer and prostate cancer by age and by 5-year interval during 1986-2005 in Taiwan (+ median age for cancer in each 5-year period).

was an unfortunate case of misguided pursuit of risk minimization. Even though scientists and urologists had access to the data, they were not fully and plainly communicating the risk to patients and the public. Until recently, few health risk assessors realized that a large number of prostate cancer deaths resulted from overuse of PSA screening tests [9-13].

\section{CASE 1: BETEL QUID (BQ) CHEWING ASSOCIATED WITH ORAL CANCER MORTALITY}

\section{Background}

\section{Oral Cancer has been Increasing and is Highly Prevalent in Taiwan}

Oral cancer mortality rates in Taiwan where it is the fourth leading type of cancer, are among the highest in the world [15]. This escalating came about only in the last 20 years after the cigarette market in Taiwan was forced open by the U.S., and BQ was heavily promoted on every street corner by a thinly clad young lady [16], euphemistically called a "betel nut Barbie." Currently, more than 1.5 million adults, mostly of lower social class, chew BQ everyday [3]. Chewers in Taiwan differ from those in countries such as India or Bangladesh, where BQ also contains tobacco, because Taiwanese chewers pick up smoking in addition to chewing $[4,17]$.

BQ consists of the areca nut, either wrapped with a betel leaf or split and sandwiched with betel fruit. Red or white lime was invariably added as a caustic to digest the areca nut and to extract the flavorful and stimulating ingredients for the chewers [3].

While IARC determined the "areca nut" to be a human group 1 carcinogen [4], and betel fruit, which contains
"Safrole" a group 2 carcinogen [4], the real hazard is the intensity and the frequency of use. With 20 cigarettes and 20 pieces of BQ a day, there would be 40 assaults to the oral mucosa every day, 365 days a year. Chewing BQ in Taiwan is associated with at least 6 types of cancer, and acting in conjunction with smoking, BQ is a systemic carcinogen, with synergistic effect with smoking [18].

\section{Risks Assessment}

One out of two chewers will die from chewing-related causes, with a hazard ratio (HR) of 2.17 for all cause mortality [3]. The life span of chewers in Taiwan has been shortened by 5 years or more [18] with a 13-fold increase in oral cancer risk attributable to BQ chewing, compared to those who were both non-chewers and nonsmokers. Oral cancer is now the leading cancer among males in their 40s in Taiwan. The median age of diagnosis for chewers with oral cancer was 52, and the median age of death was 54 [1].

The mortality rate for oral cancer has been rapidly increasing in Taiwan. In the last 20 years, the number of deaths from oral cancer in males increased 6-fold and the age-adjusted mortality rate increased 3 -fold (Table 1) [1]. In fact, Taiwan has assumed the unenviable position of leading the world in oral cancer mortality. The risk from chewing is not limited to oral cancer. It has been shown that esophageal cancer, liver cancer and lung cancer were all significantly increased among chewers [18]. It has been estimated that chewing causes nearly 20,000 deaths a year in Taiwan [8].

Much of this increase was the result of increased BQ chewing after the forced opening of the cigarette market in 1987 [16]. As most chewers also smoked, risk assessment of oral cancer based on epidemiological analysis must consider BQ chewing and tobacco smoking together [19]. The HR 
Table 1. Comparison Between Taiwan and Texas (Two Areas with Similar Population) for Betel Chewing- Abd Tobacco SmokingRelated Oral Cancer and PSA-Related Prostate Cancer

\begin{tabular}{|c|c|c|c|c|}
\hline Behavioral Risk Factor & \multicolumn{2}{|c|}{ Betel Chewing (and Tobacco Smoking) } & \multicolumn{2}{|c|}{ PSA Testing } \\
\hline Geographic Area & Taiwan & Texas, U.S. & Taiwan Male & Texas Male \\
\hline Population & 23 million & 24 million & 3 million (age $>50$ ) & 2.7 million (age $>50)$ \\
\hline $\begin{array}{l}\text { Prevalence of } \\
\text { betel chewing }\end{array}$ & $20 \%$ males & $0 \%$ & & \\
\hline $\begin{array}{l}\text { Prevalence of } \\
\text { tobacco smoking }\end{array}$ & $42 \%$ & $23 \%$ & & \\
\hline $\begin{array}{l}\text { Prevalence of } \\
\text { PSA screening }\end{array}$ & & & $<5 \%($ age $>50)$ & $60 \%$ (age > 50) \\
\hline Cancer Sites & \multicolumn{2}{|c|}{ Oral Cancer } & \multicolumn{2}{|c|}{ Prostate Cancer } \\
\hline \multicolumn{5}{|l|}{ Male } \\
\hline \# incident cases/year & 4,879 & 1,468 & 2,682 & 11,878 \\
\hline \# of deaths in 2008 & 2,079 & 700 & 980 & 1,681 \\
\hline \# of deaths in 1986 & 349 & 375 (1990) & 131 & $1,693(1990)$ \\
\hline 20-year increase in cases & 6 -fold increase $(1,740)$ & 2-fold increase (325) & 7-fold increase (759) & 0 \\
\hline $\begin{array}{l}\text { Incidence rate } \\
\text { per } 100,000\end{array}$ & 36.05 & $\begin{array}{c}15.4 \\
\text { Asian: } 10.8\end{array}$ & 25.4 & $\begin{array}{c}159 \\
\text { Asian: } 91\end{array}$ \\
\hline $\begin{array}{c}\text { Mortality rate } \\
\text { per } 100,000\end{array}$ & 15.02 & $\begin{array}{c}3.9 \\
\text { Asian: } 3.2\end{array}$ & 9.1 & $\begin{array}{c}25.6 \\
\text { Asian: } 10.6\end{array}$ \\
\hline Male/female & 13 & 2.6 & N/A & N/A \\
\hline Median Age at diagnosis & 52 & 62 & 75 & 68 \\
\hline Median Age at death & 54 & 68 & 80 & 80 \\
\hline Lifetime risk of death & $3.27 \%$ & 1.4\% Asian: $1.08 \%$ & $5 \%$ & 16\% Asian: $11.7 \%$ \\
\hline 5 -year survival & $49 \%$ & $61 \%$ & $79 \%$ & $99.9 \%$ \\
\hline \multicolumn{5}{|c|}{ Public Risk Perception } \\
\hline Risk perceived & Low & & High & \\
\hline --Voluntariness & Voluntary & & Involuntary & \\
\hline Familiarity with the risk & Familiar & & Unfamiliar & \\
\hline Perceived control & Controllable & & Uncontrollable & \\
\hline Acceptability of risk & Acceptable & & Unacceptable & \\
\hline $\begin{array}{l}\text { Factor that led } \\
\text { to cancer increase }\end{array}$ & Enjoying chewing benefits & & $\begin{array}{l}\text { Zero risk demanded, requesting } \\
\text { biopsy and surgical intervention }\end{array}$ & \\
\hline
\end{tabular}

Data sources: Taiwan: Department of Health official statistics on mortality and cancer registry. U.S., Texas: Texas Department of State Health Services ( http: //www.dshs.state.tx.us/default.shtm [14]).

for "smoking only" is 2.25 , for "chewing only" it is 10.6 and when combined it is 13.2 . While the addition of chewing to smoking has only a minor synergistic interaction, the consequence of BQ chewing for smokers is devastating, with a 6-fold increase in oral cancer mortality from smoking, a universally recognized carcinogen.

\section{Risk Perception}

The health hazards of BQ chewing, particularly for oral cancer, have long been publicized and is familiar to everyone. Nevertheless, a chewer feels that he can control the risk and quit anytime if he chooses to Since he has not been bothered by the health effects so far, the benefits he receives, or the satisfaction he gets in chewing, are sufficient to keep him going on chewing. In terms of risk perception, chewers do not view the risk from BQ chewing as sufficiently large. They are in good company, with more than one and a half million currently chewing BQ everyday. Apparently, they have heard about the oral cancer threat, but choose to ignore it. The reason for this behavior is puzzling. It is a matter of risk perception. For chewers to continue their habit, they have to deny the risk and justify their habit by perceiving the risk in one or more of the following scenarios: a) The risk has been exaggerated, b) I am different, even if the health hazards were true, c) I am just fine, and I can quit as soon as I feel otherwise, and d) It is a game of small probability. I would not be that "unlucky" to get it. The sale of BQ has been heavily promoted in every street corner with 
a thinly clad young lady in a see-through glass kiosk. It is estimated that there are more than 100,000 kiosks throughout Taiwan, more in the rural south than in the north, with $\mathrm{BQ}$ consumed more by the lower social classes than higher ones [20].

\section{Risk Communication}

Offering chewers information on the hazards of $\mathrm{BQ}$ chewing has only limited impact on their behavior. To some extent, there is a cultural and language barrier between this group and the communicators. Even with intensified "hazard information transfer," the message has not been heeded nor has it been accompanied by behavioral changes. The current governmental policy of promoting screening for oral cancer, instead of chewing cessation, as the first line prevention of chewers' health risks is fraught with problems. Screening for cancer without taking preventive measure is philosophically and strategically incorrect.

Because there is a communication gap, the effort should be re-directed, perhaps by applying lessons learned from tobacco control. WHO developed the "MPOWER" [21] strategy against tobacco. Applying the "MPOWER" approach outlined below to BQ will be effective if it can be implemented. For example, the message to quit has been largely ineffective, but if we raise the monetary cost of $\mathrm{BQ}$ chewing, the message will be heeded immediately. The amount and frequency of BQ chewing will be reduced or even discontinued if the increase in cost of consumption is sufficiently large.

M: Monitor BQ use and prevention policy

P: Protect people from BQ

O: Offer help to quit BQ use

W: Warn about the dangers of BQ

E: Enforce bans on advertising, promotion and sponsorship

\section{R: Raise taxes on BQ products}

The rationale is obvious. First, most chewers smoke, so the effort to address MPOWER will have an important impact [3]. Second, the MPOWER strategy of WHO to reduce smoking was culled from the success stories learned from tobacco control around the world in the last century. This established strategy can be applied to chewing, without re-inventing the wheel. Third, reduction of chewing will also be largely facilitated from the concept of MPOWER. For example, raising the tax will be most effective [22]. Offering cessation assistance to chewers is urgently needed through psychological counseling and pharmacological administration. The packaging requires warning labels just as in the case of tobacco.

\section{CASE 2: PSA SCREENING TEST FOR PROSTATE CANCER}

\section{Background}

\section{Prostate Cancer is Highly Prevalent in the U.S.}

Prostate cancer is the number one solid tumor cancer in U.S. men, in terms of number of new cases per year $(192,280)$ or number of living cancer patients (2.18 million). It is the second leading cause of death in the U.S. One in six men will be diagnosed with cancer of the prostate during his lifetime, higher than breast cancer, which is one in 8 women. The median age at diagnosis with prostate cancer in the U.S. was 68 years of age (Table 1). Almost none had the cancer before age 44 , and, approximately $8.7 \%$ of the cancer was diagnosed between 45 and 54; $29.0 \%$ between 55 and 64; $35.6 \%$ between 65 and $74 ; 21.4 \%$ between 75 and 84; and $4.7 \%$ over 85 [6].

For prostate cancer deaths, the median age at death was 80. No one died before the age of 44 , and $1.4 \%$ died between 45 and $54 ; 7.2 \%$ between 55 and $64 ; 20.1 \%$ between 65 and $74 ; 40.9 \%$ between 75 and 84 ; and $30.3 \%$ over 85 . In other words, $71 \%$ of the prostate cancer victims died after age 75 , an age beyond average life expectancy in many countries [6].

\section{Prostate Cancer has been Increasing Rapidly in Taiwan}

The incidence of prostate cancer has increased five-fold in 20 years in Taiwan, and the mortality rate increased threefold. Prostate cancer ranks number five in cancer incidence in Taiwan and number seven in cancer mortality. The median age of diagnosis in Taiwan is 75 years and the median age of death is 80 years [2]. Almost none had the cancer before age 40 , and approximately $2.3 \%$ of the cancer was diagnosed between 40 and $54 ; 12.4 \%$ between 55 and $64 ; 34.3 \%$ between 65 and $74 ; 43.4 \%$ between 75 and 84 ; and $7.6 \%$ over 85 (Fig. 2).

For prostate cancer deaths, the median age at death in Taiwan was 80 years of age. No one died before age 40 , and $0.7 \%$ died between 40 and 54; $5.5 \%$ between 55 and 64 ; $23.5 \%$ between 65 and 74; $47.3 \%$ between 75 and 84; and $23 \%$ over 85 . In other words, $70 \%$ of cancer victims died after age 75 .

\section{PSA Test is Available as a Simple Test for Prostate Cancer}

$\underline{\text { Study Population }}$

The cohort study: In this prospective study, the cohort consisted of 464,709 participants since 1994 in a standard medical screening program run by a private firm (MJ Health Management Institution, Taipei, Taiwan). The participants were aged 20 years and older with an average of 8.5 years follow up till 2008. They came from all walks of life and geographic areas all over Taiwan. While the fee requirement has attracted more people from the higher socio-economic class (SES), the SES distributions were able to be adjusted to those of the general population because of the large size of the cohort.

Each participant received a standardized medical screening program, starting with a questionnaire for detailed medical history and lifestyle information, followed by a battery of physical and laboratory examinations. Details of the cohort have been reported elsewhere [23].

Prostate Specific Antigen (PSA), a specific, highly sensitive test for prostate cancer approved by the U.S. FDA in 1994, is widely available, is simple to administer by testing the blood, is reasonably inexpensive, is non-invasive and is easy to obtain. Based on the cohort study experience [23], increasing PSA value was associated with a sharp increase in HRs for prostate cancer deaths (see Fig. 3). For example, the HR was 131.9-fold increase with PSA at 10 $\mathrm{ng} / \mathrm{mL}, 242.2$-fold increase with PSA at $15 \mathrm{ng} / \mathrm{mL}$ or 352.5 - 
fold increase with PSA at $20 \mathrm{ng} / \mathrm{mL}$, when compared to PSA at $3 \mathrm{ng} / \mathrm{mL}$. More than half of U.S. males had this test; with 30 million individuals at the cost of U.S. $\$ 3$ billion.

\section{Screening is a Double Edged Sword}

Screening for cancer is very popular worldwide for early detection and early intervention, as cancer is perceived as deadly. If the test is simple and inexpensive, most people would want to know whether they have cancer so that early action can be taken. With the belief that an ounce of prevention is worth of a pound of cure, prevention has been widely accepted, often without the support of epidemiological data. For example, it is generally accepted that medical screening can identify diseases at earlier stages and therefore is considered a good health practice. The medical industry offers medical screenings and the public assumes there are only benefits. Patients are often not aware that there may be risks involved with cancer screening. The goal of screening should be not just to find cancer, but to lengthen life expectancy. In addition, since healthy individuals are involved in screening, it is reasonable to expect that the test should have minimal false positives and false negatives.

\section{Risk Assessment}

At old age, prostate cancer risks exist and PSA is able to detect the cancer with high sensitivity. As shown in Fig. (3), the higher the level of PSA was, the higher the observed risk for prostate cancer [24]. The American Urological Society states that "there is no safe level of PSA below which one can be assured of not finding biopsy-detectable prostate cancer." On the other hand, prostate cancer constituted only $1.2 \%$ of all deaths in the elderly, aged $60-69$, in Taiwan, and $2.5 \%$ in the U.S. (Table 2) [12] The rate of survival after 5 years with prostate cancer is $99.9 \%$ [6] in the U.S. and $79 \%$ [2] in Taiwan. This means that the risk of dying from prostate cancer before age 70 is relatively small, when compared to many other risks in life. Let us first review the two milestone reports published last year by "The New England Journal of Medicine." One involved 182,000 men in seven European countries; [25] the other, by the National Cancer Institute, involved nearly 77,000 men at 10 medical centers in the U. S. [26]. In both, participants were randomly assigned to be screened - or not - with the PSA test. In each study, the two groups were followed for more than a decade while researchers counted deaths from prostate cancer, asking whether screening made a difference.

The American study found that the death rate was $13 \%$ lower for the unscreened group, an unexpected finding. It was concluded that there was no statistical difference in prostate cancer death rates among men who were screened, compared with men who were not.

The European data involved a consortium of studies with different designs. Taken together, the studies found that screening was associated with a $20 \%$ relative reduction in the

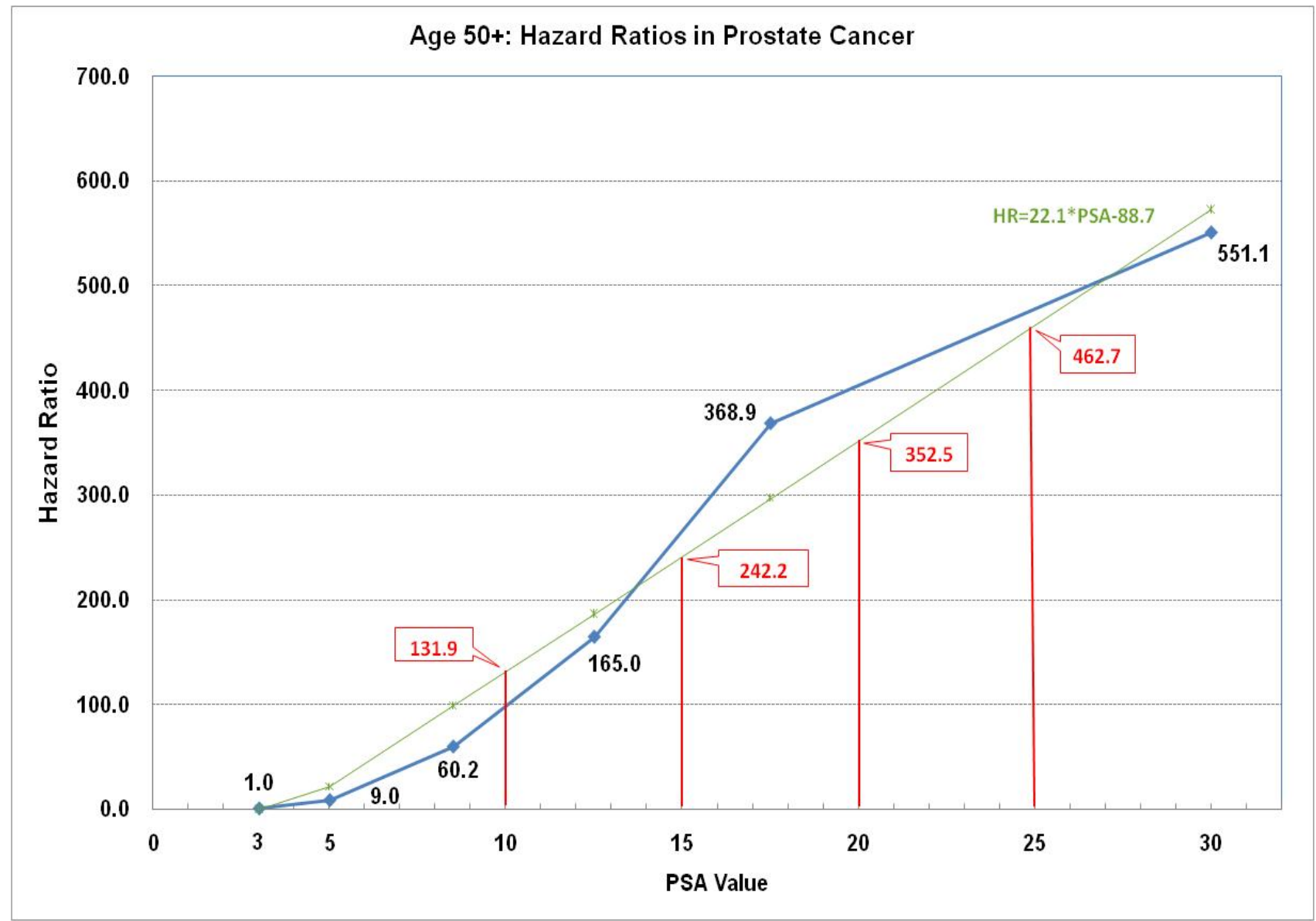

Fig. (3). Increasing hazard ratios for prostate cancer death by increasing PSA values for Age 50+. Numbers in red were predicted HRs by fitting the PSA values to the equation HR=22.1XPSA - 88.7. 
prostate cancer death rate. But the number of lives saved was small-seven fewer prostate cancer deaths for every 10,000 men screened and followed for nine years. Further, 48 men were needlessly treated for prostate cancer, with treatment side effects, for every death prevented. The reduction of $20 \%$ mortality of prostate cancer, in reality, implied that an unscreened man had a $3 \%$ risk of dying (from prostate cancer among all deaths in the next 10 years), but his risk dropped to $2.4 \%$ if the man underwent annual screenings.

While cancer treatment after a positive PSA test saves one life in 50 prostate cancer patients, there is about 49 in 50 chance that he will have been treated unnecessarily for a cancer that was never a threat to his life. As commented in the New York Times (January, 2009) the PSA blood test saves few lives and leads to risky and unnecessary treatments for large numbers of men. Clearly, this view may not be universally accepted in the medical community but it is a debate worth continuing. It points out the complexity and entwining of risk assessment, risk perception and risk communication.

\section{Risk Perception}

When confronting with the immediate health threat of prostate cancer which is real but has an unfamiliar risk, "zero risk" is demanded. All humans are fearful of cancer, and any effort to detect it early is popularly sought. Because the PSA test is noninvasive, convenient, inexpensive and recommended by the "professionals," increasingly more men are accepting the test in the U.S. and in Taiwan.

The PSA test has been and will continue to be popular, without much concern that screening for cancer could be associated with risks. With an expectation for zero risk, when faced with abnormal results of a PSA test, most will proceed to have a biopsy. And when cancer is found will invariably request treatment or surgery.

\section{Risk Communication}

The latest information on the risk associated with prostate cancer testing has rarely been communicated to those who were interested in PSA tests, not because it takes time, which it does, but because most professionals themselves are not familiar with it or choose to ignore it. The criteria requiring tested individuals be informed as seen in most recommendations (see Appendix) is ideal, but its goal is difficult to reach. This issue was made much more important by the ease of finding prostate cancer with the PSA test and biopsy technique. Everyone who is interested in the PSA test should be told about the statement made by a neutral and independent task force USPSTF (U.S. Preventive Service Task Force), published in the Annals of Internal Medicine [27], which recommends against screening for prostate cancer in men age 75 years or older and makes no recommendation in men younger than age 75 years. It concluded by stating that current evidence is insufficient to assess the balance of benefits and harms of prostate cancer screening [28]. Appendix I provides a review of current recommendations for PSA screening by different organizations in different countries worldwide. Several points should be communicated to those considering a PSA test to help them make an informed decision:
First, both the absolute and relative risk of dying from prostate cancer is small. In the older age group, the chance of death from prostate cancer among all deaths is about $1 \%$ in Taiwan and 3\% in the US. The 5-year survival rate for those with prostate cancer was $99.9 \%$ in the U.S. [6] and $79 \%$ in Taiwan [2]. Not all cancer is alike, and the behavior of prostate cancer is very unusual. With such a relatively small risk, there are many more important things to be concerned about at one's older age, other than PSA and prostate cancer.

Second, prostate cancer is common and should not be considered as life threatening. Prostate cancer was found in half of all men who underwent an autopsy for deaths from other causes. This is the reason why the American Urological Association (AUA) [29] stated that major studies have demonstrated that there is no safe PSA value below which a man may be assured that he does not have biopsydetectable prostate cancer. This implies that discovering prostate cancer through PSA and biopsy is very common and its risks should not be interpreted as life threatening.

Third, the treatment of prostate cancer is full of side effects, such as incontinence, infection, diarrhea and sexual impotence, affecting adversely the quality of the remaining life [30]. Many people who died from treatment might have survived for a long time, and died from other causes later. A review in the Annals of Internal Medicine concluded that prostate-specific antigen screening is associated with psychological harms, while its potential benefits remain uncertain [31,32].

Fourth, because there is "no safe level of PSA," [33-35] any PSA result is not safe and would create anxiety and concern for further pursuit. As a result, not doing a PSA test should be a viable option. This is consistent with the conclusion that "the harm of PSA is well established but the benefits are uncertain." [31,36]

Fifth, when PSA tests are conducted on Asians, the results should be interpreted with caution, weighing the risks and the benefits. For Asians, given the lower mortality documented so far in Taiwan (but with lower five-year survival rates thus implying higher risk from cancer treatment), a PSA of 10 is suggested as a cut-off point for considering follow-up action.

\section{Discussion}

These case studies showed the power of risk perception while ignoring evidencefrom risk analysis based on epidemiological data. The consequences in both instances were tragic in Taiwan, with 2,000 deaths from oral cancer and 1,000 deaths from prostate cancer occurring every year. Many of the deaths were entirely preventable.

Richard Ablin, the man who invented the PSA test 40 years ago, in an article entitled "The Great Prostate Mistake" [37] in the "New York Times" on March 9, 2010, said that " the PSA test's popularity has led to a hugely expensive public health disaster, with 30 million men tested in the U.S., at the cost of $\$ 3$ billion dollars, having little or no reduction in mortality" He continues, "Most $(70 \%)$ prostate cancers do not cause harm and do not need treatment, and for the remaining $30 \%$ with aggressive prostate cancer, whether screening improves the odds of survival remains a matter of debate." Dr. Therese Bevers, the medical director of the 
cancer prevention center at the University of Texas M. D. Anderson Cancer Center said, "Patients often are not aware that there are risks associated with cancer screening." (New York Times, October 21, 2009).

For screening to be effective it must prolong life, not just detect prostate cancer. Times have changed and health professionals are beginning to acknowledge that "early detection" is not the absolute answer to cancer. And many are recognizing that what seems a simple diagnostic test can carry more risks than benefits.

A cursory review of recent recommendations made by most professional organizations revealed that most organizations take a neutral stand by helping patients to be an informed decision maker. It should be clear from this study that a brief visit to the doctor's office is inadequate to cover all the ramifications of PSA tests. It is also clear that the large disparity of medical information between patients and the professionals cannot be bridged in a short period of time. Leaving the decision to the patient will work toward the professional's advantage. Besides, not taking a stand is much safer.

\section{Frequency of PSA Testing Directly Associated with an Increase in Prostate Cancer Incidence}

Strong evidence of the relationship between PSA use and prostate cancer incidence came both from the U.S. experience and internationally. The incidence patterns observed in the U.S. and Canada suggest a strong relationship to prostate-specific antigen (PSA) test use [38]. Comparison between the U.S. and UK was particularly revealing in that incidence in the U.S. was much higher than in the UK, but the two countries had similar mortality rates from prostate cancer $[39,40]$. Much of this difference in incidence was because more than half in the U.S. (57\%) age 50 or older had PSA test in the previous 12 months but only $6 \%$ of those older than age 45 in the UK had a PSA test.

\section{Difference Between Taiwan and U.S._Racial or Artificial}

Although evidence is accumulating against the widespread use of PSA, the prospect for a fresh look at this issue is bleak for countries like the U.S., where the practice has already become standardized. However, in countries like Taiwan where PSA testing is still limited but on the verge of a large increase, the need to evaluate or to communicate the risk of the PSA test is important and urgent.

Mortality from prostate cancer among Asians is much lower than among American Caucasians (Fig. 4). The average 10-year probability of dying from prostate cancer after age 50 is $0.53 \%$ in Taiwan compared to $1.13 \%$ in the U.S. Prostate cancer deaths constituted $1.5 \%$ of all deaths among males after age 50 in Taiwan, compared to $3.17 \%$ in
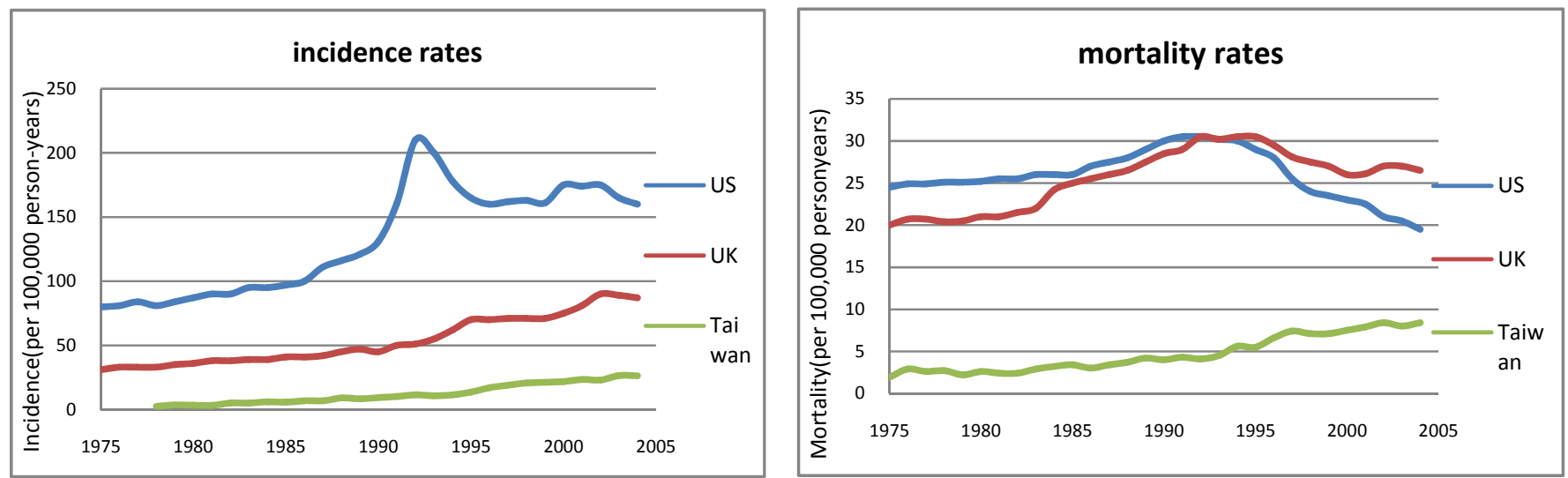

Fig. (4). Comparison of incidence rates and mortality rates for prostate cancer among U.S., UK and Taiwan men between 1975 and 2005 , showing higher incidence rates in the U.S. than in UK, but with similar mortality rates between the two countries, and rates for Taiwan were the lowest. Source: Plots for U.S. and UK quoted from Collin SM, et al. 2008. Incidence data for Taiwan came from Cancer Registry System and mortality data from Taiwan DOH official statistics. Taiwan data were age-adjusted to the 2003 European Standard Population [41].

Table 2. Proportion of Deaths Due to Prostate Cancer Among Males in Taiwan and White Male in the U.S. [12]

\begin{tabular}{|c|c|c|c|c|c|c|c|c|}
\hline & \multirow{2}{*}{$\begin{array}{c}\text { Population } \\
\text { (2008) }\end{array}$} & \multirow{2}{*}{$\begin{array}{l}\text { 10-Year Probability } \\
\text { of Dying }\end{array}$} & \multicolumn{2}{|c|}{ 10-Year Incidence } & \multicolumn{2}{|c|}{ 10-Year Mortality } & \multicolumn{2}{|c|}{ \% Prostate Cancer (PC) Deaths Among All Deaths } \\
\hline & & & Taiwan & U.S. & Taiwan & U.S. & Taiwan & U.S. \\
\hline $40-49$ & $1,896,680$ & $5.80 \%$ & $0.04 \%$ & $0.93 \%$ & $0.01 \%$ & $0.02 \%$ & $0.17 \%$ & $0.36 \%$ \\
\hline $50-59$ & $1,555,072$ & $11.40 \%$ & $0.38 \%$ & $4.26 \%$ & $0.06 \%$ & $0.15 \%$ & $0.53 \%$ & $1.27 \%$ \\
\hline $60-69$ & 769,333 & $27.10 \%$ & $1.48 \%$ & $8.53 \%$ & $0.32 \%$ & $0.68 \%$ & $1.18 \%$ & $2.53 \%$ \\
\hline $70-79$ & 533,048 & $63.80 \%$ & $2.68 \%$ & $8.47 \%$ & $1.19 \%$ & $2.44 \%$ & $1.87 \%$ & $3.81 \%$ \\
\hline$\geq 80$ & 269,595 & $14.00 \%$ & $2.89 \%$ & $6.62 \%$ & $2.53 \%$ & $5.42 \%$ & $1.81 \%$ & $3.87 \%$ \\
\hline Total $(50+)$ & $3,127,048$ & $35.28 \%$ & $1.26 \%$ & $6.23 \%$ & $0.53 \%$ & $1.13 \%$ & $1.50 \%$ & $3.17 \%$ \\
\hline
\end{tabular}

Source: Taiwan incidence and mortality: Department of Health. U.S. incidence and mortality: Surveillance, Epidemiology and End Results (SEER) Program 2001-2005 (white males only). 
Table 3. Distribution of PSA Values for Taiwan (Extrapolated from Cohort Data) [23] Compared with U.S. Prevalence Data

\begin{tabular}{|c|c|c|c|c|c|c|c|c|c|}
\hline Age & No. Cohort Subjects with PSA Test & Mean (S.D.) ng/mL & Median ng/mL & Taiwan & U.S & Taiwan & U.S & Taiwan & U.S \\
\hline $20-29$ & 2187 & $0.8(0.6)$ & 0.7 & $0.6 \%$ & NA & $0 \%$ & NA & $0.6 \%$ & NA \\
\hline $30-39$ & 7028 & $0.8(0.7)$ & 0.7 & $0.6 \%$ & NA & $0.1 \%$ & NA & $0.7 \%$ & NA \\
\hline $50-59$ & 11,558 & $1.2(1.6)$ & 0.9 & $2.6 \%$ & $3.8 \%$ & $0.3 \%$ & NA & $2.9 \%$ & $3.8 \%$ \\
\hline $60-69$ & 8,010 & $1.9(3.6)$ & 1.1 & $7.7 \%$ & $6.9 \%$ & $1.6 \%$ & $1.1 \%$ & $9.3 \%$ & $8.0 \%$ \\
\hline $70-79$ & 2,858 & $2.7(4.3)$ & 1.5 & $14.1 \%$ & $16.2 \%$ & $3.4 \%$ & $3.3 \%$ & $17.5 \%$ & $19.5 \%$ \\
\hline$\geq 80$ & 370 & $4.8(13.8)$ & 1.5 & $13.5 \%$ & $22.7 \%$ & $7.3 \%$ & $6.3 \%$ & $20.8 \%$ & $29.0 \%$ \\
\hline$\geq 60$ & 11,238 & $2.2(4.5)$ & 1.2 & $10.9 \%$ & $12.8 \%$ & $3.1 \%$ & $2.7 \%$ & $14.1 \%$ & $15.5 \%$ \\
\hline
\end{tabular}

Age group prevalence was standardized to Taiwan population (2006). Data source for the U.S: David A, et al. 2006 [42] (NHANES2001-2004 data).

the U.S. white men. Incidence in the U.S. for aged 50 or older (average $6.23 \%$ in ten years) is 5 times more than in Taiwan $(1.26 \%)$ (Table 2$)$.

These large differences in incidence may not be all racial, however. Incidence in the U.S. was 5 times higher and mortality 2 times higher than in Taiwan, while the distribution of PSA values was nearly identical between the two countries (Table 3 ). This raised the possibility that much of the incidence increase and its subsequent increase of mortality rate were associated with higher PSA testing in the U.S. population. The adoption of PSA screening is far less among Asians than in the U.S. More than half of U.S. males aged 50 or older $(60 \%)$ had a PSA tests in the last 12 months. In contrast, it is much less than 5\% in Taiwan.

\section{PSA Screening Recommendation for Asians should be Based on risk Assessment Using Epidemiological Data}

Documented evidence shows that as more PSA tests are conducted in a society, the recorded incidence of prostate cancer will increase [43]. By having so many PSA tests done in the U.S., the false positive rate is bound to increases sharply. The incidence and mortality rates have both been rapidly increasing in Taiwan in the last 20 years, $331 \%$ and $175 \%$, respectively, between 1985 and 2005, compared to $27 \%$ and $-27 \%$ in the U.S. in the same period (Table 4).

We have made the following observations: 1) Lower mortality in Asians in Taiwan involved higher false positive rates, 2) PSA screening carried confirmed risks but uncertain benefits, 3) 5-year survival was lower in Taiwan than in the U.S., implying higher treatment-related mortality, 4) Prostate cancer death is a very small risk compared with other risks, 5) the AUA stated that there is no safe level of PSA below which biopsy-detectable cancer will not exist, implying any PSA result is worrisome, and 6) PSA testing in Taiwan is still limited and knowing that more PSA testing would lead to more mortality, we propose: "Not performing the PSA test should be a viable option, even though prostate cancer risk in the elderly is real." If the test were to be conducted, we propose that follow up action should be considered only for those with a PSA $>10$.

This will exclude $80 \%$ of those $>4$ but only about one quarter of potential cancer victims (27\%) with a PSA value between 4 and 10. Even with a PSA > 10, only one in 50 with cancer will die from the cancer. If all with a PSA $>4$ received a biopsy, and those with a positive biopsy received full treatment, then at least 30 men would have been unnecessarily treated for a man whose death from cancer was prevented.

\section{RISK ASSESSMENT AND COMMUNICATION IN CLINICAL SETTINGS}

In every clinical encounter, a doctor examines a patient and analyzes his clinical history, signs and symptoms in order to assess his risk. The basis of these assessments of clinical data comes from text books where epidemiological data of the past was analyzed and assimilated. How epidemiological data translate into risk assessments varies by the nature of the data and the availability of detailed epidemiological findings.

Measures used in clinical and epidemiologic practice consist of both absolute risk and relative risk. The line between absolute and relative risk may not be clear cut, but in general, absolute risk includes mortality rates, life expectancy or remaining years of life, the probability of dying in the next 5-10 years, or life time probability of dying from a specific cause (or case fatality rate), while relative risk includes HR and standardized mortality (or incidence) ratios (SMR or SIR).

Appendix II illustrates risk assessments actually taking place in clinical settings on a daily basis, although they may not be considered risk assessments per se. The following can be considered risk assessments in clinics.

\section{Blood Pressure Readings or Fasting Blood Sugar Values}

Epidemiological data in Taiwan showed that all cause mortality and cardiovascular mortality was increased by $54 \%$ 
Table 4. Comparison of Change Over Time in Age-Adjusted Prostate Cancer Incidence and Mortality Per 100,000 and Incidence/Mortality Ratio Between Taiwan and U.S. for Age 50 and Older, Using U.S. 2000 Population as Standard

\begin{tabular}{|c|c|c|c|c|c|c|}
\hline & \multicolumn{2}{|c|}{ Incidence (Per 100,000) } & \multicolumn{2}{|c|}{ Mortality (Per 100,000) } & \multicolumn{2}{|c|}{ Ratio (Incidence/Mortality) } \\
\hline 1985 & 26 & 416 & 16 & 122 & 1.6 & 3.4 \\
\hline 1990 & 36 & 615 & 19 & 139 & 1.9 & 4.4 \\
\hline 2000 & 91 & 645 & 36 & 109 & 2.5 & 5.9 \\
\hline 2005 & 112 & 530 & 44 & 89 & 2.5 & 6.0 \\
\hline$\%$ change from 1985 to 2005 & $331 \%$ & $27 \%$ & $175 \%$ & $-27 \%$ & & \\
\hline
\end{tabular}

Source: Taiwan incidence and mortality: Department of Health. U.S. incidence and mortality: Surveillance, Epidemiology and End Results (SEER) Program 2001-2005 (white males only) [44].

$(\mathrm{HR}=1.54)$ among those with systolic blood pressure above $140 \mathrm{mmHg}$ (Appendix II), when compared with those below that level. This is relative risk. We need absolute risk to make the relative risk relevant. For healthy individuals, the absolute 10-year risk from dying is $5.8 \%$ for those between the ages 40 to 49 and $27.1 \%$ for those between the ages 60 to 69 , but for the hypertensive, the probability increases to $8.9 \%$ and $41.7 \%$, respectively. Similarly, those with a fasting blood sugar above $126 \mathrm{mg} / \mathrm{dL}$ were found to have a $106 \%$ higher all cause mortality $(\mathrm{HR}=2.06)$ than were those with lower fasting blood sugar. As a result a doctor would counsel the patient to reduce his blood pressure or blood sugar either by medication or by life style changes such as physical activity or weight loss. When blood pressure drops to 120 or below the increased risk disappears, but if it remains at 130$139 \mathrm{mmHg}$, there would be a $14 \%$ increase in all cause mortality risk $(\mathrm{HR}=1.14)$. Risk also remains elevated in the case when fasting blood sugar is only reduced to $110-125$ $\mathrm{mg} / \mathrm{dL}$, a level labeled as impaired fasting glucose (Appendix II).

\section{History of Smoking or BQ Chewing}

Smokers in Taiwan who do not chew have an all-cause mortality risk increase of $68 \%(\mathrm{HR}=1.68)$ compared with those who neither smoke nor chew. Chewers in Taiwan who do not smoke also have an increase of mortality by $68 \%(\mathrm{HR}=1.68)$, but when combined with smoking, the mortality rate increases by $127 \%(\mathrm{HR}=2.27)$, almost doubling the smoking risk alone (Appendix II). Unfortunately, most chewers (90\%) in Taiwan also smoke.

\section{Obesity}

Those with a $\mathrm{BMI} \geq 30$ had a $19 \%$ increase in mortality risk, compared with those with a BMI between 18 and 22.9. A waist circumference $\geq 100$ in males $\mathrm{cm}$ (Appendix II) had an $84 \%$ $(\mathrm{HR}=1.84)$ increase in all-cause mortality risk, compared with?

\section{Multiple Risk Factors}

Most risks when combined with another risk may increase synergistically. For example, when diabetes was added to hypertension, the CVD risks increased from nearly 4-fold $(\mathrm{HR}=3.9)$ to 6 -fold $(\mathrm{HR}=6.2)$. When smoking was added, the risk became 7 -fold $(\mathrm{HR}=7.1)$

\section{SUMMARY AND CONCLUSION}

Health risk assessment in the clinical setting, based on epidemiological studies, is critical in medical practice. It helps patients understand the urgency of the medical condition and to identify the priorities. More importantly, patients are expected to take action. The issue is not only important but also valuable in daily practice because many patients are given multiple drugs (pharmacies) and instructions to follow, and often more than one diagnosis. The compliance of a patient improves if he/she knows which drug or instruction has a higher priority and requires immediate attention. For example, instruction to take a certain drug may be given along with drinking less sweetened drinks and exercising more at the same time. Are they equally important? It seems strange to note that this "clinical risk assessment" has received very little attention so far and most patients are on their own and oftentimes at a loss. It also follows that the equally important area of addressing risk perception in conjunction with risk communication has also been neglected. In this paper, two case studies are used to illustrate the implications of risk assessment, risk perception and risk communication and how they can lead to different consequence, or conclusions.

Mainstream risk assessment, mostly for regulatory purposes, has focused on toxic substances involving small risks at current (frequently low) exposure levels. Most of these assessments address risks at a magnitude between one per thousand and one per million. Risks in clinical settings are several orders of magnitude higher, like one out of three in life time risk from smoking. The irony is that the general public is far more concerned with toxic substances than lifestyle or clinical risks. This discrepancy is a major health threat and should alarm the risk assessors who are pursuing technological excellence on a continuing basis. Effective communication of risk in clinical settings should be a required discipline for clinicians. It should address the gap between the perceived risk, commonly dominated by pre-conceived notions, and the actual risk, derived from evidence-based data.

\section{ACKNOWLEDGEMENT}

This study is supported by Taiwan Department of Health Clinical Trial and Research Center of Excellence (DOH 99TD-B-111-004). 


\section{APPENDIX I}

\section{A Review of Current Recommendations for PSA Screening}

The following lists the organizations most prominent in their position for PSA screening. Most stated carefully in not discouraging the patients in requesting PSA by emphasizing the "informed" patient, a term unlikely to be met in reality.

1) The USPSTF [31] concludes that the current evidence is insufficient to assess the balance of benefits and harms of prostate cancer screening in men younger than age 75 years. The USPSTF recommends against screening for prostate cancer in men age 75 years or older.

2) The American Cancer Society (ACS) [45] does not support routine testing for prostate cancer at this time.

ACS does believe that health care professionals should discuss the potential benefits and limitations of prostate cancer early detection testing with men before any testing begins. This discussion should include an offer for testing with the prostate-specific antigen (PSA) blood test and digital rectal exam (DRE) yearly, beginning at age 50, to men who are at average risk of prostate cancer and have at least a 10-year life expectancy.

Following this discussion, those men who favor testing should be tested. Men should actively take part in this decision by learning about prostate cancer and the pros and cons of early detection and treatment of prostate cancer.

3) Article: Benefits and Harms of Prostate-Specific Antigen Screening for Prostate Cancer: An Evidence Update for the U.S. Preventive Services. Ann Intern Med. 2008; 149: 192-199 [31]

Conclusion: Prostate-specific antigen screening is associated with psychological harm, and its potential benefits remain uncertain.

4) American Urological Association. PSA test should be offered to well-informed men aged 40 years or older who have a life expectancy of at least 10 years. Benefits and risks of screening for prostate cancer should be discussed, including the risk of over-detection (detecting some cancers which may not need immediate treatment). There is no single standard that applies to all men.

Major studies have demonstrated that there is no safe PSA value below which a man may be reassured that he does not have biopsy-detectable prostate cancer. Therefore, the AUA does not recommend a single PSA threshold at which a biopsy should be obtained. Rather, the decision to biopsy should take into account additional factors, including free and total PSA, PSA velocity and density, patient age, family history, race/ethnicity, previous biopsy history and comorbidities. The AUA statement emphasizes that not all prostate cancers require active treatment and that not all prostate cancers are life-threatening.

5) U.S. Preventive Services Task Force [27]. For men younger than age 75 years, the benefits of screening for prostate cancer are uncertain and the balance of benefits and harm cannot be determined. For men 75 years or older, there is moderate certainty that the harms of screening for prostate cancer outweigh the benefits.

6) Cancer Council Australia. No recommendation for or against prostate cancer screening. Men should weigh the pros and cons before deciding to be screened.

7). European Urological Association. Current published data are insufficient to recommend population screening for prostate cancer as a public health policy owing to the large overtreatment effect.

8) Japanese Urological Association. The evidence for the effect of prostate cancer screening is insufficient. PSA and digital rectal examination are not recommended for population-based screening programs.

9) National Health Committee (New Zealand). Given the lack of conclusive evidence showing reduction in morbidity or mortality, population-based or opportunistic screening for prostate cancer using PSA or digital rectal examination for asymptomatic men is not recommended but a man should not be denied the test if he is fully informed and requests it.

10) Swedish Board Of Health And Welfare. No recommendations about general PSA screening for men aged 50-70, but providers should provide information to men who are interested in screening.

(11) National Health Service (UK). No organized screening program for prostate cancer, but provide informed choice program, Prostate Cancer Risk Management, aiming to provide high quality information about the risks and benefits to men who ask about screening in order to enable them to decide whether or not to have the test. 


\section{APPENDIX II}

Table 1. Relative Risks (Hazard Ratios) Age and Gender Adjusted for Commonly Measured Values in Clinical Settings (Cohort Data from MJ Health Management Institution was used for this Analysis)

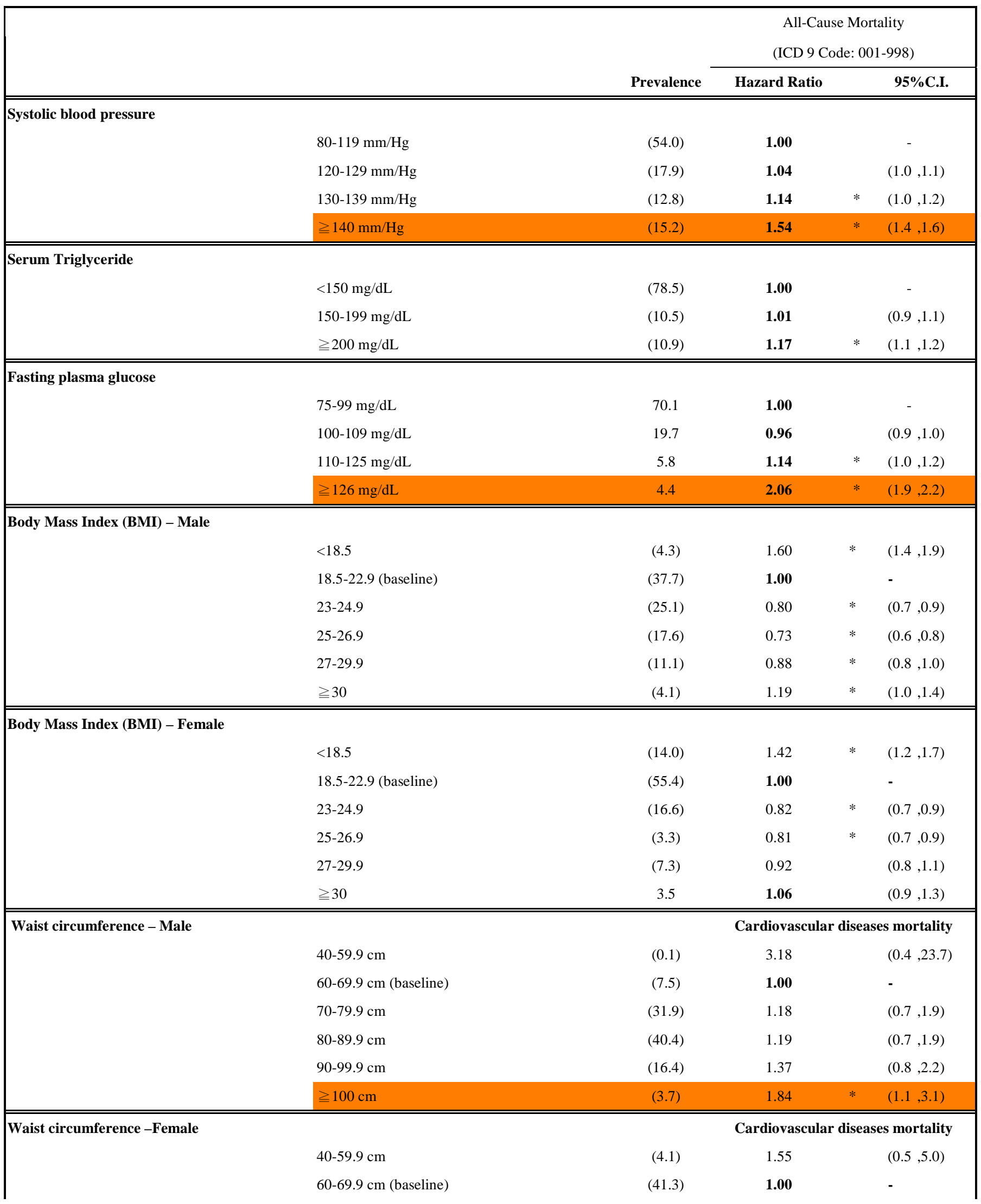


(APPENDIX II) contd......

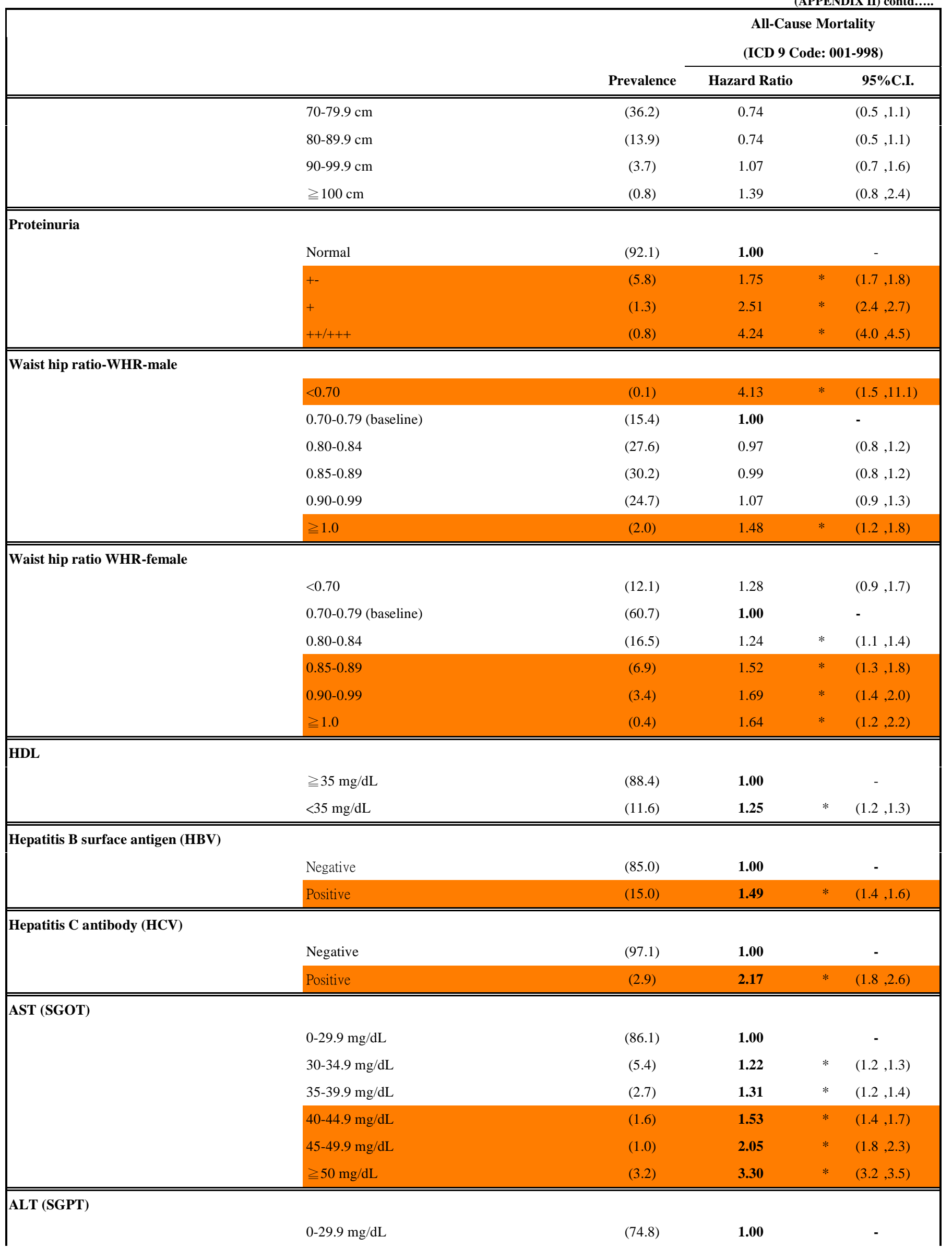


(APPENDIX II) contd......

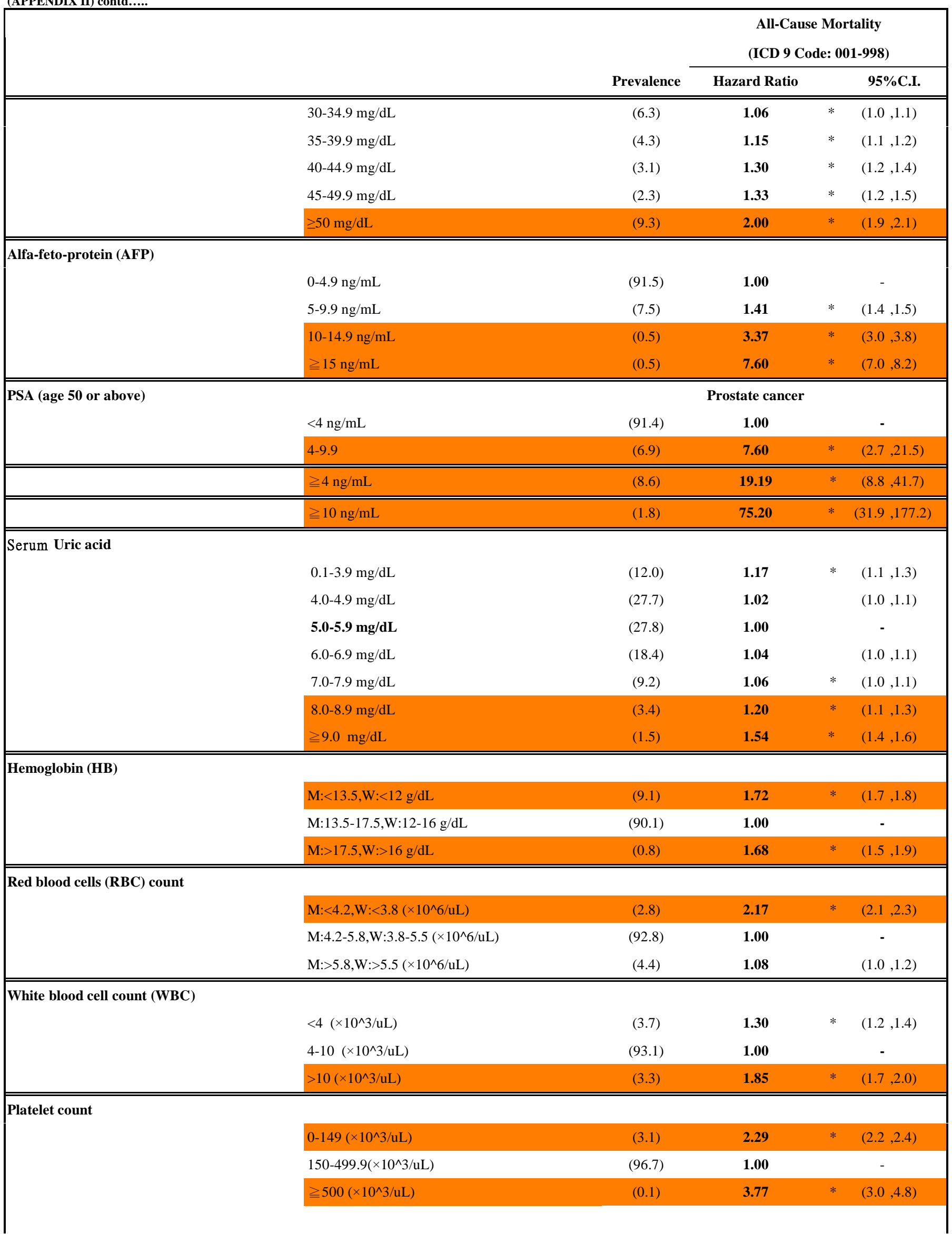


APPENDIX II) contd......

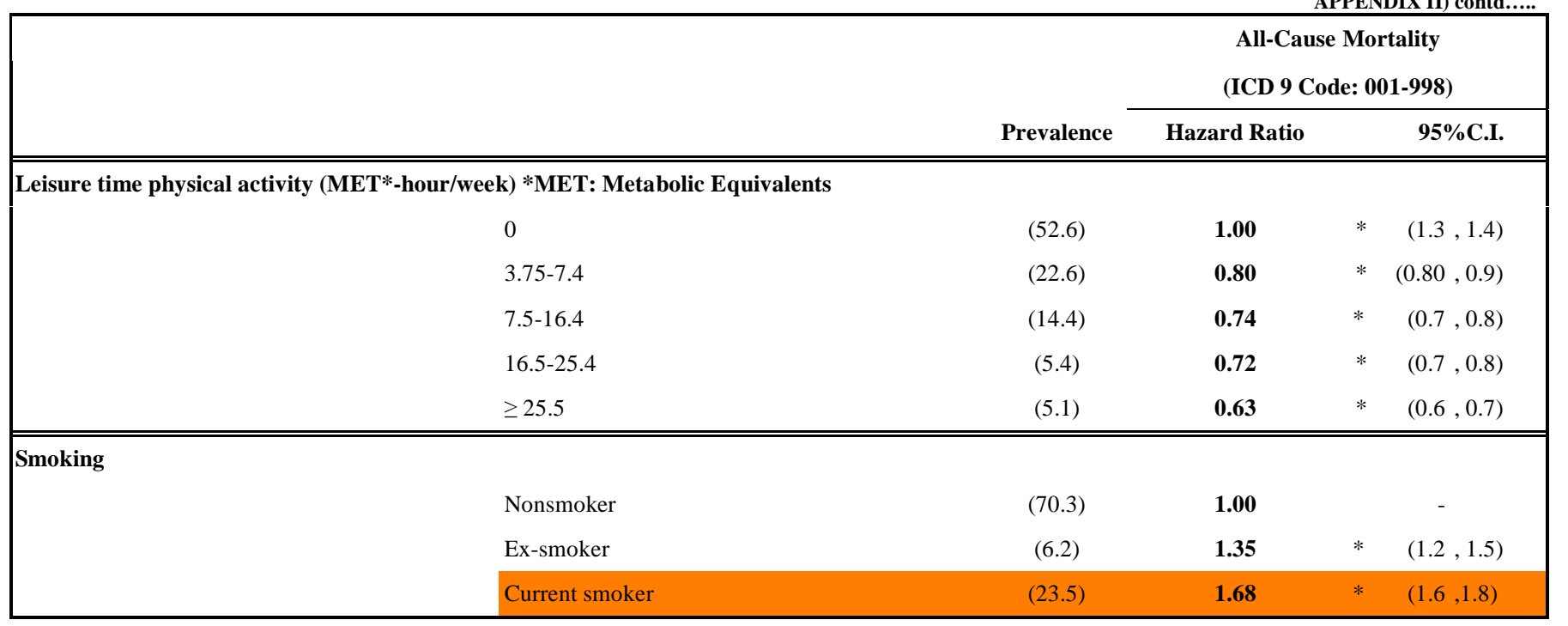

\section{REFERENCES}

[1] Department of Health Executive Yuan T. Age adjusted mortality from leading cancer causes of death by gender. Vital Statistics in Taiwan.(In Chinese). Taipei, Taiwan: Health Statistics in Taiwan 1986-2006.

[2] Kademani D. Oral Cancer. Mayo Clin Proc. 2007; 82: 878-87.

[3] Wen CP, Tsai SP, Cheng TYD, et al. Uncovering the relation between betel quid chewing and cigarette smoking in Taiwan. Tob Control 2005; 14: i16-22.

[4] IARC Working Group on the Evaluation of Carcinogenic Risks to Humans. Overall Evaluations of Carconogenicity to Humans. Group 1: Carcinogenic to humans. Lyon, France: World Health Organization 2004.

[5] Ko YC, Huang YL, Lee CH, Chen MJ, Lin LM, Tsai CC. Betel quid chewing, cigarette smoking and alcohol consumption related to oral cancer in Taiwan. J Oral Pathol Med 1995; 24:450-3.

[6] Lee CH, Lee JM, Wu DC, et al. Independent and combined effects of alcohol intake, tobacco smoking and betel quid chewing on the risk of esophageal cancer in Taiwan. Int J Cancer 2005;113: 47582.

[7] Lee C-H, Wu D-C, Lee J-M, et al. Anatomical subsite discrepancy in relation to the impact of the consumption of alcohol, tobacco and betel quid on esophageal cancer Int J Cancer 2007;120:1755-62.

[8] Wen CP, Tsai MK. Chan HT. The contribution of betel quid chewing to the smoking attributable mortality in Taiwan. Presented at the 2010 Asia Pacific Conference on Tobacco or Health (APACT), Sydney, Australia 2010.

[9] Brawley OW, Ankerst DP, Thompson IM. Screening for prostate cancer. CA Cancer J Clin 2009; 59:264-73.

[10] Barry MJ. Screening for prostate cancer--the controversy that refuses to die. N Engl J Med 2009; 360:1351-4.

[11] Hoffman RM. Viewpoint: limiting prostate cancer screening. Ann Intern Med 2006;144: 438-40.

[12] Welch HG, Schwartz LM, Woloshin S. prostate-specific antigen levels in the United States: Implications of Various Definitions for Abnormal. J Natl Cancer Ins 2005;97: 1132-7.

[13] Welch HG, Albertsen PC. Prostate cancer diagnosis and treatment after the introduction of prostate-specific antigen screening: 19862005. J Natl Cancer Inst 2009;101:1325-9.

[14] TEXAS Department of State Health Services. Data and Reports, Center for Health Statistics (Available from: http://www.dshs.state.tx.us/default.shtm). 2010.

[15] SEER Cancer Stat Fact Sheets. Cancer of the Oral Cavity and Pharynx. (http://seer.cancer.gov/statfacts/html/oralcav.html). National Cancer Institute.

[16] Wen CP, Cheng TY, Eriksen MP. How opening the cigarette market led to an increase in betel quid use in Taiwan. Public Health 2005;119:940-4.

[17] Gupta P, Warnakulasuriya S. Global epidemiology of areca nut usage. Addict Biol 2002;7:77-83.
[18] Wen CP, Tsai MK, Chung WSI, et al. Cancer risks from betel quid chewing beyond oral cancer: a multiple-site carcinogen when acting with smoking. Cancer Causes Control 2010; (In press).

[19] Wen CP, Cheng TY, Chen CJ, Levy DT, Yang HJ, Eriksen MP. Uncovering the relationship between betel quid chewing and cigarette smoking in Taiwan. Tobacco Control 2005;14(s1):i16-22.

[20] Wen CP, Cheng CW, Cheng TY, et al. Trends in betel quid chewing behavior in Taiwan- Exploring the relationship between betel quid chewing and smoking. (In Chinese). Taiwan J Public Health 2009; 28:407-19.

[21] WHO Report of the Global Tobacco Epidemic. 2008: The MPOWER package Geneva: World Health Organization 2008 (Available from http://www.who.int/tobacco/mpower/en/).

[22] Lee J-M. The synergistic effect of cigarette taxes on the consumption of cigarettes, alcohol and betel nuts. BMC Public Health 2007;7:121-8.

[23] Wen CP, Cheng TYD, Tsai MK, et al. All-cause mortality attributable to chronic kidney disease: a prospective cohort study based on 462293 adults in Taiwan. Lancet 2008; 371: 2173-82.

[24] Loeb S, Roehl KA, Antenor JA, Catalona WJ, Suarez BK, Nadler RB. Baseline prostate-specific antigen compared with median prostate-specific antigen for age group as predictor of prostate cancer risk in men younger than 60 years old. Urology 2006; 67: 316-20.

[25] Schroder FH, Hugosson J, Roobol MJ, et al. Screening and prostate-cancer mortality in a randomized European study. N Engl J Med 2009; 360: 1320-8.

[26] Andriole GL, Crawford ED, Grubb RL, et al. Mortality results from a randomized prostate-cancer screening trial. N Engl J Med 2009; 360: 1310-9.

[27] Force USPST. Screening for Prostate Cancer: U.S. Preventive Services Task Force Recommendation Statement. Ann InternMed 2008;149:185-91.

[28] Walter LC, Bertenthal D, Lindquist K, Konety BR. PSA screening among elderly men with limited life expectancies. J Am Med Assoc 2006; 296: 2336-42.

[29] Peter C, Albertsen M, Kirsten G, Richard J, Babaian MH, et al. Prostate-Specific Antigen Best Practice Statement:2009 Update. Am Urol Assoc 2009.

[30] Wilt TJ, MacDonald R, Rutks I, Shamliyan TA, Taylor BC, Kane RL. Systematic review: comparative effectiveness and harms of treatments for clinically localized prostate cancer. Ann Intern Med 2008; 148: 435-48.

[31] Lin K, Lipsitz R, Miller T, Janakiraman S. Benefits and harms of prostate-specific antigen screening for prostate cancer: an evidence update for the U.S. Preventive Services Task Force. Ann Intern Med 2008; 149:192-9.

[32] Concato J, Wells CK, Horwitz RI, et al. The effectiveness of screening for prostate cancer: a nested case-control study. Arch Intern Med 2006; 166: 38-43. 
[33] Porter MP, Stanford JL, Lange PH. The distribution of serum prostate-specific antigen levels among American men: implications for prostate cancer prevalence and screening. Prostate 2006; 66:1044-51.

[34] Vis AN, Kranse R, Roobol M, van der Kwast TH, Schroder FH. Serendipity in detecting disease in low prostate-specific antigen ranges. BJU Int 2002; 89:384-9.

[35] Thompson IM, Ankerst DP, Chi C, et al. Operating characteristics of prostate-specific antigen in men with an initial PSA level of 3.0 ng/mL or lower. J Am Med Assoc 2005;294:66-70.

[36] Lim LS, Sherin K, Committee APP. Screening for prostate cancer in US men ACPM position statement on preventive practice. Am J Prev Med 2008; 34:164-70.

[37] Ablin R. The Great Prostate Mistake. New York Times 2009.

[38] McDavid K, Lee J, Fulton JP, Tonita J, Thompson TD. Prostate cancer incidence and mortality rates and trends in the United States and Canada. Public Health Rep 2004;119:174-86.

[39] Collin SM, Martin RM, Metcalfe C, et al. Prostate-cancer mortality in the USA and UK in 1975-2004: an ecological study. Lancet Oncol 2008; 9: 445-52.

[40] Oliver SE, Gunnell D, Donovan JL. Comparison of trends in prostate-cancer mortality in England and Wales and the USA. Lancet 2000; 355:1788-9.
[41] Yen AM-F, Chen L-S, Chiu Y-H, Boucher BJ, Chen TH-H. A prospective community-population-registry-based cohort study of the association between betel-quid chewing and cardiovascular disease in men in Taiwan (KCIS no. 19). Am J Clin Nutr 2008; 87:70-8.

[42] Connolly D, Black A, Gavin A, Keane PF, Murray LJ. Baseline prostate-specific antigen level and risk of prostate cancer and prostate-specific mortality: diagnosis is dependent on the intensity of investigation. Cancer Epidemiol Biomarkers Prev 2008;17:2718

[43] Lu-Yao G, Albertsen PC, Stanford JL, Stukel TA, Walker-Corkery ES, Barry MJ. Natural experiment examining impact of aggressive screening and treatment on prostate cancer mortality in two fixed cohorts from Seattle area and Connecticut. BMJ 2002; 325:740.

[44] IARC Working Group on the Evaluation of Carcinogenic Risks to Humans. Betel-quid and areca-nut chewing and some areca-nutderived nitrosamines. IARC Monogr Eval Carcinog Risks Hum 2004; 85:1-334.

[45] Smith CJ, Perfetti TA, Garg R, Hansch C. IARC carcinogens reported in cigarette mainstream smoke and their calculated $\log \mathrm{P}$ values. Food Chem Toxicol 2003;41:807-17.

(C) Wen et al.; Licensee Bentham Open.

This is an open access article licensed under the terms of the Creative Commons Attribution Non-Commercial License (http://creativecommons.org/licenses/by$\mathrm{nc} / 3.0 /$ ) which permits unrestricted, non-commercial use, distribution and reproduction in any medium, provided the work is properly cited. 